\title{
Action Research to Enhance Inter-Organisational Coordination of Climate Change Adaptation in the Pacific
}

\author{
Daniel Gilfillan ${ }^{1,2, * \mathbb{D}}$, Stacy-ann Robinson ${ }^{3}(\mathbb{C})$ and Hannah Barrowman ${ }^{4}$ \\ 1 International Centre for Environmental Management, Hanoi, Vietnam \\ 2 Fenner School of Environment and Society, The Australian National University, Canberra ACT 0200, Australia \\ 3 Environmental Studies Program, Colby College, Mayflower Hill Drive, Waterville, ME 04901, USA; \\ smrobins@colby.edu \\ 4 Centre for Deliberative Democracy and Global Governance, University of Canberra, Bruce ACT 2617, Australia; \\ hannah.barrowman@canberra.edu.au \\ * Correspondence: daniel.gilfillan@anu.edu.au
}

Received: 8 April 2020; Accepted: 21 May 2020; Published: 27 May 2020

\begin{abstract}
Pacific regional organisations focusing on climate change have overlapping adaptation-related mandates. With the growing importance of regional organisations in supplying financial and technical resources for climate adaptation in small island developing states, it is important to understand how well these supranational organisations work together on these issues. In this paper, theories of regionalism and neofunctionalism, complex systems, and superordinate group identity are used to design an action research project that tests the level of coordination between Pacific regional organisations. It presents and discusses a pre-analysis plan for the project, the goal of which is to determine the ways in which virtual team structure can be used to enhance inter-organisational coordination of adaptation interventions across small, dispersed, resource-constrained country jurisdictions. The proposed study represents an important intermediary step in developing more robust climate-related organisational policies at the regional scale in the Pacific and beyond.
\end{abstract}

Keywords: action research; climate change adaptation; coordination; Pacific; regional organisations; small island developing states; superordinate group identity; virtual team structure

\section{Introduction}

Regional organisations (ROs) are increasingly providing the financial and technical resources needed to support climate change adaptation in small island developing states (SIDS), a special grouping of countries that are disproportionately vulnerable to the impacts of climate change [1]. There are 58 SIDS located in three main geographic regions, including the Pacific [2]. The 20 Pacific SIDS, like the other SIDS globally, are particularly vulnerable to a range of climate change impacts that include rising sea levels, increases in sea-surface temperatures, and changes in rainfall patterns [3,4]. The vulnerability of SIDS results from factors including their smallness, reliance on natural systems, remoteness and distance from world markets, and financial and technical resource constraints [5]. These development and sustainability challenges are exacerbated by climate change and highlight the need for appropriate and effective adaptation to climate change in order to avoid the loss of livelihood-supporting ecosystem services and infrastructure in SIDS $[3,6]$. 
Climate change adaptation is the 'process of adjustment to actual or expected climate and its effects' ([7], p. 1758). The aim of adaptation in the human system is to 'moderate or avoid harm or exploit beneficial opportunities' ([7], p. 1758). In this context, ROs can (and already do) play a critical role in coordinating and implementing adaptation action that seeks to reduce vulnerabilities and increase resilience to the impacts of climate change in SIDS [8,9]. Despite this, not enough is known about how ROs are coordinating and can better coordinate adaptation across small, dispersed, resource-constrained country jurisdictions. To address this knowledge gap, this paper presents an action research design for testing and enhancing the level of coordination between two ROs at the forefront of climate change action in the Pacific-the Pacific Community (SPC) and the Secretariat of the Pacific Regional Environmental Programme (SPREP) (see Supplementary Materials File S1 for more details). These organisations have a long and complicated history of overlapping mandates, especially in relation to developing and implementing climate change adaptation initiatives across Pacific SIDS [1,10,11]. Pacific SIDS, like the SIDS in the other two geographic regions (the Atlantic and Indian Oceans, and the Caribbean), rely on international financing to offset the cost of adaptation initiatives, yet the volume of international adaptation financing is lower than recipient country expectations and needs [12]. As a result, organisations including SPC and SPREP have found themselves competing for funding from the same pool.

To examine the ways in which Pacific ROs can reduce competition for scarce funding, we propose to explore, alongside RO staff and personnel, how virtual team structure can help SPC and SPREP better work together to fight the threat of climate change. Increased coordination between the organisations is likely to reduce the perception of an existing rivalry in addition to each organisation seeing the other as a threat or obstacle to accessing their 'fair share' of international adaptation financing through such mechanisms as the Green Climate Fund (GCF) (see Supplementary Materials File S2 for more details).

In our action research design, we randomly assign SPC and SPREP staff to mixed member virtual teams. There are two primary factors underlying our decision to propose this approach that works with research participants to 'co-learn' about how the two ROs operate and the motivations and/or constraints they experience. First, there is limited knowledge of how ROs interact with each other and coordinate their actions in and across small islands. Second, SPC and SPREP are small organisations, and the small sample sizes would prevent us from conducting a big- $N$ quantitative experiment. Consideration of these two factors led us to conclude that an action research approach, with a strong emphasis on co-enquiry and co-learning among researchers and participants, is among the most appropriate avenues of enquiry for understanding motivations of and constraints to RO coordination among small, dispersed, resource-constrained country jurisdictions in the Pacific, at least in the initial stages.

The virtual teams that we establish during the research will work together over a six-month period to produce a 'bankable' adaptation project proposal for submission to the GCF. During the course of this action research project, we will collect and analyse qualitative data, including through (a) semi-structured interviews with participants, (b) facilitated reflective periods between researchers and participants, (c) observing team meetings, (d) administering short surveys, and (e) the evaluation of each team's project proposal by an independent judging panel. We will use the qualitative evidence collected to support recommendations for ways to enhance the level of coordination between SPC and SPREP. The results of the action research will also have relevance to the other two Pacific ROs that are also coordinating adaptation action across multiple SIDS- the Pacific Islands Forum, and the University of the South Pacific.

Our approach is novel because action research has yet to be used as a method to explore coordination challenges between sustainability focused ROs, and particularly those in the Pacific. Action research is particularly useful in contexts where the focus is on gaining insights and on doing so in a collaborative manner. Further, when inquiry focuses on social organisation and interaction, action research can help co-researchers to inquire into their own practice, learn from experience, and thus act and interact more consciously. The action research approach is, therefore, well-suited for use early on in the knowledge 
production and co-production process. To the best of our knowledge, our research presents the first action research to better understand $\mathrm{RO}$ coordination for adaptation in the Pacific.

To achieve our central aim, the remainder of this paper is divided into five sections. The following section outlines the background and context of our work, covering regional service delivery for climate change adaptation in the Pacific. Section 3 describes our theoretical framework. Section 4 presents our action research plan, including outlining our three research questions, identifying variables, describing the research procedure as well as our approach to data collection and analysis. Section 5 discusses the proposed design, including the advantages and limitations of action research in this context. Section 6 summarises the key messages and design elements highlighted in the paper. Together, this proposal represents an important intermediary step in developing more robust, climate-related organisational policies at the regional scale in the Pacific and beyond.

\section{Background and Context}

\subsection{Regional Service Delivery for Climate Change Adaptation in the Pacific}

Regional service delivery, wherein ROs coordinate climate adaptation-related services 'that are normally provided at the national or subnational level', has been advocated as a means of addressing development and sustainability challenges in the Pacific ([13], p. 541). ROs provide support across a range of sectors, including food security, water resources management, and coastal management, which are central to Pacific resilience and sustainability (see [11,14,15]). According to Haas [16], ROs are subsets of international organisations created for cooperative action to address shared problems. 'Regional' here refers to 'supranational' regions as opposed to 'subnational' regions. Examples of ROs in the Pacific include SPC, SPREP, the Pacific Islands Forum, and the University of the South Pacific because they (a) represent pan-Pacific groupings, (b) have multi-sectoral mandates, (c) were established by formal intergovernmental agreements, (d) have national governments as members, and (e) seek to address shared problems (based on $[16,17])$. Regional service delivery is not new in the Pacific and is considered to be a factor encouraging Pacific regionalism $[11,13]$. ROs also facilitate burden sharing, reduce transaction costs, and assist with the development and maintenance of specialised knowledge [17].

\subsection{ROs Coordinating Climate Change Adaptation in the Pacific}

Increasing resource scarcity and competition between ROs strengthen the case for inter-organisational coordination underpinned by specific, measurable, achievable, results-focused, and time-bound goals and objectives. Here, coordination is the 'degree to which each of the various interdependent parts of a ... system operates according to the requirements of the other parts and of the total system' ([18], p. 84). 'Collaboration', 'cooperation', 'integration', and 'conflict' are also often used to designate 'coordination' [18]. Levels of coordination link closely to the effectiveness of ROs. For example, Robinson and Gilfillan [1] used three case study organisations to examine the adaptation-related effectiveness of ROs in the Caribbean and Pacific, and identified poor coordination as inhibiting effectiveness. The authors, following Etzioni [19], defined effectiveness as the degree to which an organisation realises its goals. They found that the organisations are most effective in terms of their adaptation-related inputs and outputs but less so in terms of their adaptation-related projects/programs. They also found that the two ROs at the forefront of climate action in the Pacific-SPC and SPREP—have overlapping adaptation-related mandates that put constraints on their ability to deliver services effectively across small, dispersed, resource-constrained countries.

The findings in Robinson and Gilfillan [1] present several insights for deconstructing the challenges of regional-level adaptation governance in the Pacific. While SPC and SPREP signed a Memorandum of Understanding for resilience and sustainable development in 2017 [20], the Pacific Islands Forum, another 
$\mathrm{RO}$, announced climate change as part of its own competence [21]. This move could be seen as a broader strategy on its part but it is in line with what Bryar and Naupa ([15], p. 155) call 'the shifting tides of Pacific regionalism'. It is also symptomatic of the increasing number of ROs 'specialising' in climate action and, therefore, competing for climate financing in a way that has been previously referred to in the literature as a 'turf war' (e.g., see [10], p. 24). Additionally, international adaptation financing is consistently well below pledged levels, and there is evidence that the 'pie' could be shrinking [22]. The individual pursuit of scarce financial resources for adaptation in SIDS, without deliberate and purposeful coordination, negatively impacts organisational effectiveness and sustainability at the regional level.

\subsection{Group Structures for Effective Inter-Organisational Coordination}

Case study evidence from the broader Asia-Pacific region suggests that the establishment of technical working groups and similar mechanisms, whose members often meet virtually, is insufficient for increasing inter-organisational coordination. Technical working groups have been used extensively in Cambodia, for example, to support work across multiple sectors and government agencies, which are considered separate organisations because of their varying mandates and structures, through which officials are inclined to protect their own areas of responsibility [23]. The success of technical working groups, however, has been limited, mostly due to a lack of prioritisation on the part of the government, visible through factors such as meetings not being held unless funding is forthcoming from external donor agencies to incentivise participation [23]. Though the Framework for Pacific Regionalism and other regional-level policy documents prioritise climate change adaptation in the Pacific (see [24]), the Cambodian example highlights that the establishment of mechanisms and structures such as technical working groups is not sufficient in itself to ensure successful and effective inter-organisational coordination.

Because organisations are becoming increasingly geographically dispersed and making increasing use of information and communication technologies, especially since the recent outbreak of COVID-19, virtual teams are now being studied in a variety of disciplines. The number of field studies (as opposed to laboratory-based studies) is also increasing [25]. The body of literature examining performance and success markers of virtual teams, for example, in single, profit-making, multinational corporations is expansive (e.g., [26,27]). However, research on the impact of virtual team structure on inter-organisational coordination within a regional (as opposed to multiregional) context is sparse. The design of the action research project presented here aims to help fill this gap.

\subsection{Action Research for Co-Learning about RO Coordination Challenges in the Pacific}

Action research is a way of approaching a broad research agenda, rather than a strict method in itself [28]. Its goal is participatory action and co-learning, where research participants are co-researchers rather than the subjects of research, and researchers are co-learners rather than the external and objective formulators and analysers of scientific problems [29]. Thus, the principal qualities of action research are engagement, mutual curiosity, and the seeking of insights into issues of a significant and practical nature [30]. The participatory aspect of action research means that the external researchers must be open to new insights, learnings and evolutions as a fundamental part of the co-learning process. As part of the co-learning process, action research tends to have periods of action in which practices are tested and evidence is gathered, followed by periods of reflection where the actions and evidence are assessed and used to make plans for further action [30]. To this end, action research can be seen as a 'common endeavour for common goals' ([29], p. 38). Thus, it is well-suited to our particular research problem, given that the mandates of Pacific ROs, including those of SPC and SPREP, focus strongly on working with Pacific island nations to improve their individual and collective environmental, social, economic, and political circumstances (e.g., see [1]). 
A recent study by Robinson ([31], p. 14) called for more action-based research 'where those working on the frontlines of operationalizing climate change activities in SIDS are also provided with opportunities to collaborate with academics and co-produce knowledge that is locally-relevant and outside the academe'. Our proposal answers this call and positions us to explore a particular aspect of action research in which we are interested-the role of facilitation in collaborative teams and in reflecting on actions. While there are multiple definitions and conceptualizations of 'facilitation' [32], we see it as the act and art of engaging co-researchers in a continual process of co-discovering, co-developing, and co-applying learning insights. According to Wilkinson ([33], p. 2), one of the fundamental 'secrets' of facilitation is its ability to support the achievement of 'more effective results' -its use and/or incorporation as an organisational tool or strategy means that 'solutions are created, understood and accepted by the people impacted'. This aside, Raelin ([34], p. 83) acknowledged that facilitation is often 'delimited within group settings as assisting members to accomplish their goals through a focus on process rather than on content'. As a result, we adopt a 'model of action research', which responds to and begins to address the shortcoming identified by Raelin [34] and which aims to resolve some of 'the contradictions and choices of facilitative practice by regarding it as a continual process of inquiry' ([32], p. 615).

Later in this paper, we will explain that two of the four virtual teams that we will establish will have team leaders who will function as facilitators (see Section 4.2.2). We see this more as 'facilitation embedding' as we acknowledge that facilitation, in and of itself, requires extensive training and complex skills [35]. The external researchers will also facilitate reflections on actions in the two teams with structure. We will, consequently, pay special attention to applying its four dimensions-(a) the purpose of the group, organisation, or community; (b) the theoretical conceptualisation which the facilitators bring to their meaning making of the events; (c) the wider field or context in which they are operating; and (d) the energy or atmosphere in the group at any particular time and the choreography of that energy ([32], p. 615). We, therefore, aim to understand how these four dimensions of facilitation shape, or are shaped by, (a) the environment in which SPC and SPREP operate, (b) how organisations function internally, and (c) how people identify with an organisation and with work teams.

\section{Theoretical Framework}

Our research focuses on the use of inter-organisational virtual teams to develop a regionally focused, 'bankable' climate change adaptation project proposal. In order to account for the three different levels of theorising involved, we have framed our research with theories that provide insights into (a) the environment in which SPC and SPREP operate (neofunctionalism and regionalism), (b) how organisations function internally (complex systems thinking), and (c) how people identify with an organisation and with work teams (superordinate group identity). Figure 1 provides a graphical representation of how these different theoretical elements fit together.

As an initial step in addressing the identified knowledge gaps in the literature, we expect that the implementation of our study will uncover currently unknown aspects of RO coordination in the Pacific. Additionally, while there has been much research done on coordination within organisations, there is a paucity of empirical research on the impact of coordination on inter-organisational effectiveness in the environmental sustainability domain. Thus, our action research design offers an initial step into this important field of research that is being increasingly defined by the growing importance of ROs, and the growing number of organisations involved in climate adaptation-related work, especially at the regional level. 


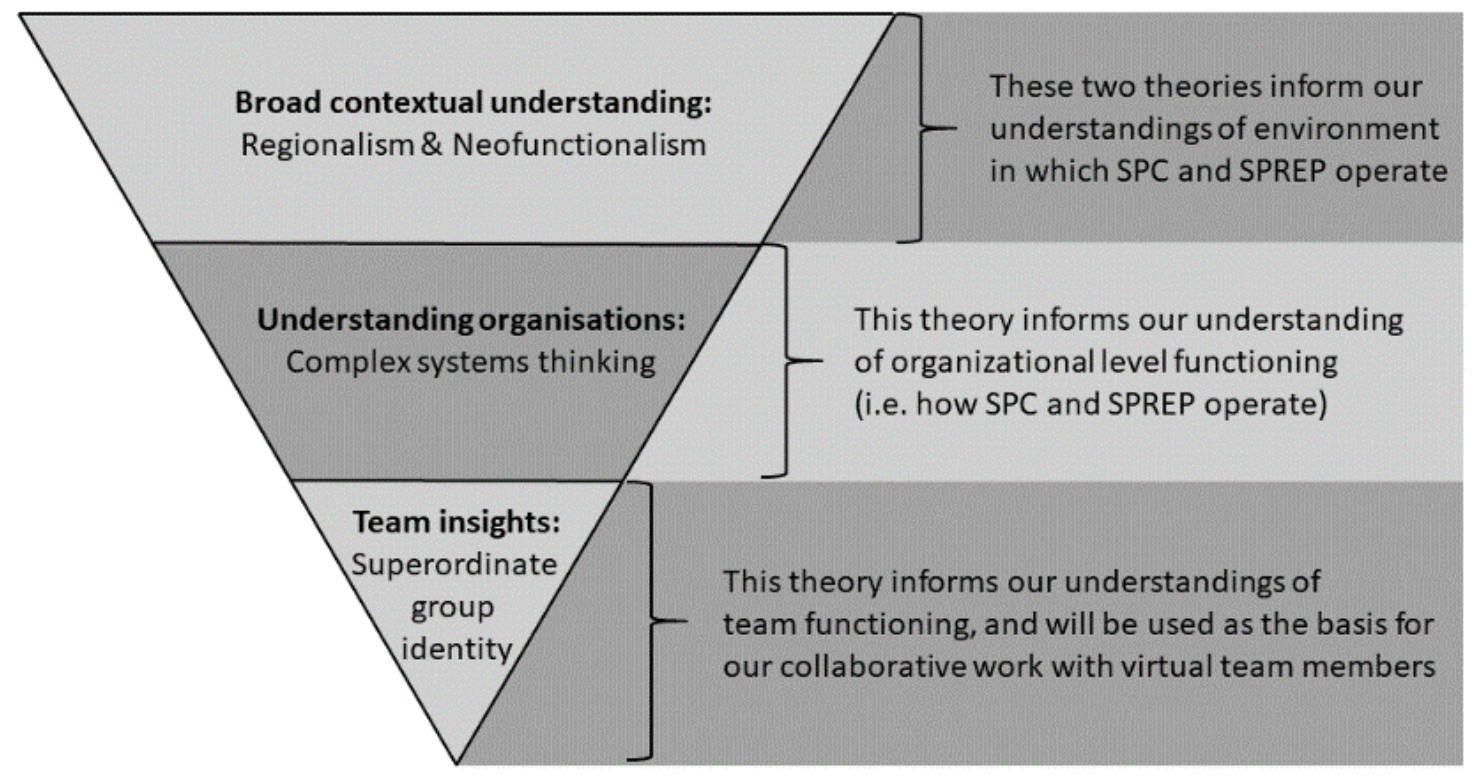

Figure 1. Links between theories (source: authors).

\subsection{Regionalism and Neofunctionalism}

As our first 'operating environment' theory, regionalism represents a complex process of change that can be triggered from subnational and intraregional levels wherein actors and processes at various scales interact with each other [36]. Regionalism can refer to formal projects and/or processes, or more narrowly, 'the body of ideas, values and polices that are aimed at creating a region' ([37], p. 3). According to Engel, et al. ([38], p. 3), the 'most tangible form of regionalism is its institutionalization in a regional organisation'. Because of the geographical distance separating the island nations of the Pacific, the essence of the ROs' role requires a degree of 'virtuality'. Here, virtuality is defined as the extent to which 'team members use virtual tools to coordinate and execute team processes, [and] the amount of informational value provided by such tools' ([39], p. 700). Virtuality can have significant impacts on team performance, planning processes and structural support (e.g.,see $[40,41]$ ), especially in the context of inter-organisational coordination and effectiveness.

For our research, neofunctionalism adds to our application of regionalism. In fact, neofunctionalism is one of a range of approaches used in the study of regionalism-it combines ideas of functionalism and federalism [42]. While functionalism's and federalism's approaches to regionalism are more concerned with constitutional design (i.e., they are premised on the idea that form follows function), the basic mechanism of concern in neofunctionalism is that of 'spillover'. Spillover is defined as 'the way in which the creation and deepening of integration in ... [one] sector would create pressures for further integration within and beyond that ... sector, and greater authoritative capacity' at the regional level (cited in [43], p. 14). For our research, enhancing inter-RO coordination is a key aspect of neofunctionalism's focus on deepening regional integration. For example, from a neofunctional perspective, deliberate institutional design is 'the most effective means for solving common problems' ([42], p. 16). Institutions can be formal, informal and multiscale, and have 'predictable arrangements, laws, processes or customs serving to structure political [and] social ... relationships' ([44], p. 222). Though 'embedded in complex, interactive systems of multiple institutions, organizations and actors' ([44], p. 222), their design and structure provide a foundation as well as incentives for coordination. They are important for creating functional and political spillover, maintaining regionness, and transforming regional cooperation and associated initiatives [45,46]. Building further on the neofunctionalism perspective, we use the idea of transformation to refer to an adaptation or 
change that radically or fundamentally adjusts the way organisations interact with their external operating environment (see [47]). Incentivising transformation underscores the importance of regionalism being viewed as an intentional process of coordination, collaboration and cooperation in pursuit of sustainable development within and of a region.

\subsection{Complex Systems Thinking}

Moving from the broader context in which SPC and SPREP operate down to the level of the organisations themselves, we approach their operation from a complex systems thinking perspective. Complexity links to regionalism and neofunctionalism with Haas [48], for example, seeing it as often deriving directly from a neofunctionalist perspective of regionalism. According to Meadows ([49], p. 2), a system can be defined as 'a set of things interconnected in such a way that they produce their own pattern of behaviour over time'.

Organisations are dynamic, comprised of multiple dimensions, and have multiscale and interlinking goals and objectives [50]. From a systems perspective, there are two theoretical principles that are relevant here. First, organisations are open systems comprised of interconnected and mutually-dependent subsystems [51]. Being mutually dependent, there are circular relationships between the overall system and its parts [52], with the effectiveness of each subsystem impacting on the effectiveness of other subsystems as well as on the overall system itself [53]. Second, the primary goal of organisations (as systems) is to ensure their own survival [53]. They must adapt to changes in their general and specific environments in order to maintain a steady state [51]. Goal attainment and adaptation are among the most critical functional imperatives [53].

This descriptor of organisations as systems treats them with a level of rationality and predictability that is not always apparent in the interactions of the people who comprise them. For example, in Kurtz and Snowden's [54] work on complexity and the Cynefin framework, the authors note that people hold more than one identity and thus may act or react in different ways depending on the immediate context, including whether a person is acting or reacting as an individual or as part of a broader collective. In examining inter-organisational coordination, the human element becomes important. Thus, the two principles outlined in the previous paragraph (i.e., organisations are open systems, and the primary goal of organisations, as systems, is to ensure their own survival) become more complex when objective ideals are replaced by the understanding that different people can perceive the same situation in different ways [54]. Coordination requires people from different parts of an organisation to work together towards the achievement of organisational goals [51] The level of coordination can be influenced by the environment and the individuals involved, as well as by the way decisions are made and communications managed [51]. How different parts of organisations are placed physically (i.e., located together or separately) and organisationally (i.e., strength of the connection between them), the variability and complexity of subgroups and their members, and the design and patterns of relationships and communication are, therefore, important drivers of the level of intra- and inter-organisational coordination [51].

\subsection{Superordinate Group Identity}

As our research focuses on how teams work together within and across SPC and SPREP, we also aim to understand inter-organisational team functioning. The third component of our theoretical framework is, therefore, superordinate group identity. Superordinate group identity explores how task orientation can bring together members of separate groups. The purpose is to strengthen the bonds within the combined (inter-organisational) team or group so that this new team comes to have a similar or higher-level of importance to the members of the team than their bonds with their original group. In other words, our research will develop insights into the ways in which members of the virtual inter-organisational teams 
can be encouraged to develop a sense of 'team' identity that transcends their identification with either SPC or SPREP (e.g., see [55,56]). This concept is linked to the Common Ingroup Identity Model [57,58], which asserts that, in order to reduce intergroup bias, strategies should attempt to re-categorise the intergroup situation so that in- and outgroup(s) become subsumed into a more inclusive superordinate category. Thus, changing members' perceptions of group boundaries enables some of the cognitive and motivational processes that may have contributed initially to ingroup bias to be redirected toward the development of more positive intergroup relationships. Higher identification with the superordinate group can lead to less bias (of the other) and a greater willingness to accept the merging of the ingroup and outgroup or, in our case, the merging of two different and sometimes competing organisations. As the focus is on a task-oriented identity, it is only within the confines of the task that the superordinate group identity will manifest; the research focus is not about employee loyalty.

In our research into $\mathrm{RO}$ coordination, superordinate group identity asks how members of two or more ROs working jointly to produce a 'bankable' adaptation project proposal could be encouraged to more meaningfully coordinate their actions, so that each virtual team functions as a single cohesive unit rather than as separate teams or sub-groups. As an initial step to address this issue, this action research proposal puts theoretical concepts around group formation into practice. Specifically, the proposed research is designed to compare how different factors that the theory tells us contributes to the formation of group identity interact to improve the performance of an inter-organisational working group.

\section{Pre-Analysis Plan}

Within our framework of action research, co-researchers (i.e., RO staff and personnel) are likely to have insights and inputs that will change the way the project is carried out. Despite the changes that may occur, a clear understanding on our part of what we hope to achieve will be important for guiding the overall research as well as to show SPC and SPREP directors-general the value that the research will provide to the respective organisations. Here, we therefore present a pre-analysis plan for our qualitative action research project. Developing and publishing this plan ahead of conducting the research adds transparency to the process, with peer review and publication being important steps in helping us to increase the robustness of our research methodology [59]. As far as we are aware, this is the first use of an action research approach to study coordination between ROs that are addressing global commons issues.

\subsection{Research Questions}

As an action research project, we are entering the research with an open mind and are not in search of definitive answers. However, as the first step towards gathering detailed data on how to best enhance coordination between geographically separated organisations working to address global commons issues, we have developed three questions to guide the conduct of the research:

1. Are there particular aspects of virtual team structure that could increase inter-organisational coordination across two sustainability focused ROs?

2. Do changes in virtual team structure have an observable impact on the effectiveness or ability of team members working together across both sustainability focused ROs?

3. Are there observable links between virtual team structure and facilitation of reflections, and any emergence of superordinate group identity?

We have deliberately developed open research questions to allow for unexpected outcomes to develop from this research (see [30]). This is an appropriate first step in better understanding coordination between sustainability focused ROs. 


\subsection{Operationalising Variables}

Despite being an action research project with a focus on participation and openness to unexpected outcomes, we have built the research design loosely around the notion of a qualitative field experiment. Thus, we have incorporated two key variables that will help direct research toward the research questions outlined in Section 4.1. These two key variables are inter-organisational coordination and virtual team structure. How we define and operationalise each of them is explained below. We should, however, point out that while the proposed action research is designed to search for relationships, as it is the first research in this area of which we are aware, and because of its open-ended nature, causal factors may not be clearly identified during the conduct of the research (e.g., see [60]). Theories of action 'provide a very simple, but powerful, tool for getting beneath the surface of individual, group, and organizational behavior'; they 'systematically analyze and document behavioral patterns and the reasoning behind them' ([61], p. 254]). Future research should, therefore, aim to 'identify the causal connections that [further] explain [the] effectiveness or ineffectiveness' of varying structures of virtual teams in this context ([61], p. 254).

\subsubsection{Inter-Organisational Coordination}

There is significant research that highlights how poor coordination between organisations undermines responses to climate change globally (e.g., $[1,62,63])$. Building on this, our proposed research will use (a) semi-structured interviews with co-researchers, (b) observations and participation in meetings and other actions, (c) facilitated reflections (for two of the four virtual teams), and (d) results-based assessments to test the level of coordination between the two target organisations prior to and following the completion of the research project.

In assessing levels of coordination, we will consider both the operational environment and the people in the two organisations. Our particular interest will be the way that people communicate with each other, including how organisational structures and processes influence communications and the solving of common problems. From a neofunctional approach to regionalism, the design of these arrangements, whether formal, informal and/or multiscale, influences the level of coordination (see [42]). From a complex systems thinking approach, these are among the factors that influence coordination within and across the system (see [51]). Considering the Common Ingroup Identity Model, that explains superordinate group identity formation $[57,58]$, it is the extent to which the people can work together to reduce intergroup bias, and the strategies that can be used to re-categorise intergroup configuration so that in- and outgroup(s) become subsumed into a more inclusive superordinate category. In other words, for the task at hand (i.e., virtual inter-organisational teams co-developing a 'bankable' climate change adaptation funding proposal for the GCF), how the external researchers and co-researchers can most effectively build a sense of team identity that is stronger than team members' identification with either SPC or SPREP. As shown in Figure 3, pre- (T1) and post-tests (T2) of the level (s) of inter-organisational coordination will be conducted. As part of these tests, co-researchers will be asked two levels of questions, those that relate to (a) themselves as individuals working in their respective organisations (individual level) and (b) how the processes and protocols in their respective organisations support (or hinder) coordination and communication with other organisations that also work for the common good. With regard to (b), questions will also cover perceptions of coordination and communication between SPC and SPREP. An example of an individual-level question is how co-researchers, personally, interact with people who work in the other organisation. At the organisational level, we are interested in questions that relate to the quantity and frequency of inter-organisational communications as well as the responsiveness of each organisation at the organisational level. 


\subsubsection{Virtual Team Structure}

Virtual teams have two common features-members are geographically dispersed and consequently have little face-to-face interaction. Most interactions are facilitated by information and communication technologies [64]. While there are several different parameters/dimensions that affect virtuality [65], geographic dispersion and technology usage are the two most common [66]. Our research focuses on these two. In this study, geographic dispersion will be measured as a single item, and following Kirkman et al. [67], virtual team members will be asked to indicate the number of times they met face-to-face, if at all, over the duration of the study. It is also possible to measure geographic dispersion as an aggregate composite of multiple components. Suh and Shin [68], for example, asked team members to indicate whether they work at the same location as each person on their team. The authors used these scores to measure team-level geographic dispersion. In order to measure technology usage, team members will be asked to indicate the percentage of communication that occurred via different media. Rice and Gattiker [69] suggest a general order of media, from rich (face-to-face interaction) to poor (numerical information). These can then be weighted or used for qualitatively understanding the match (or mismatch) between 'task-information processing requirements' and a 'medium's ability to convey information richness' ([70], p. 295).

Four virtual inter-organisational teams, similar to technical working groups, will be established as part of this action research project. Working with virtual teams in climate/sustainability-focused ROs is innovative, as studies of virtual teams typically examine performance and success markers in profit-making, multinational corporations (e.g., see [26,27]). The proposed study is also highly relevant as the number of multinational organisations utilising virtual teams is increasing, especially in view of the new technologies that are available [25], and the recent outbreak of COVID-19, which is likely to spur even more usage of online platforms and various configurations of virtual team structures in the shortand long-terms.

Two of the four virtual teams will have a formal 'structure' (see Figure 2 and Supplementary Materials File S3 for more details on team structure, roles and tasks). Here, structure refers to 'the basic configuration of the team in terms of the locations and the roles of members' ([64], p. 366). The configuration will relate to the roles of team members but also to the tasks to be undertaken over the course of the action research project, more specifically. Each of these two teams will have a team leader. Team leaders will be SPC or SPREP officers and can be seen as either internal facilitators, offering 'support for groups in [their] own organization, as an internal service', or as internal practitioners who are domain experts who 'can run a single recurring collaboration process without support of a professional facilitator' ([35], p. 134). Facilitated reflections in these teams will be conducted by the external researchers. In these roles, the external researchers can be seen as either external facilitators, offering 'process support for groups outside the organization where they work, usually in a consultant role', or as external practitioners who are domain experts, running 'a single recurring collaboration process without support of a professional facilitator' ([35], p. 134). Within these facilitation contexts, a number of facilitation-related skills will be important for the SPC and SPREP officers, and the external researchers, in their roles as team leaders and reflection facilitators, respectively. These skills range from tolerating and creating silence, to leading/creating, and following the team agenda [32]. Here, it is important to acknowledge that 'there is a paradox in facilitation' ([71], p. 20). The influence of facilitators, whether internal or external, can affect the nature and quality of the teams' outcomes. That being said, it would be unrealistic to expect facilitators to be completely impartial. It would also be unwise to ignore that internal facilitators are likely to have their own political agendas, which may or may not align squarely with the aims and objectives of the research project [71]. While these are not easily overcome, O'Flynn and Wanna ([72], pp. 118-119) suggested that a 'strong project 
process with accountabilities throughout to ensure milestones and outcomes are achieved' is important for managing interactions and promoting collaboration in team-based environments.

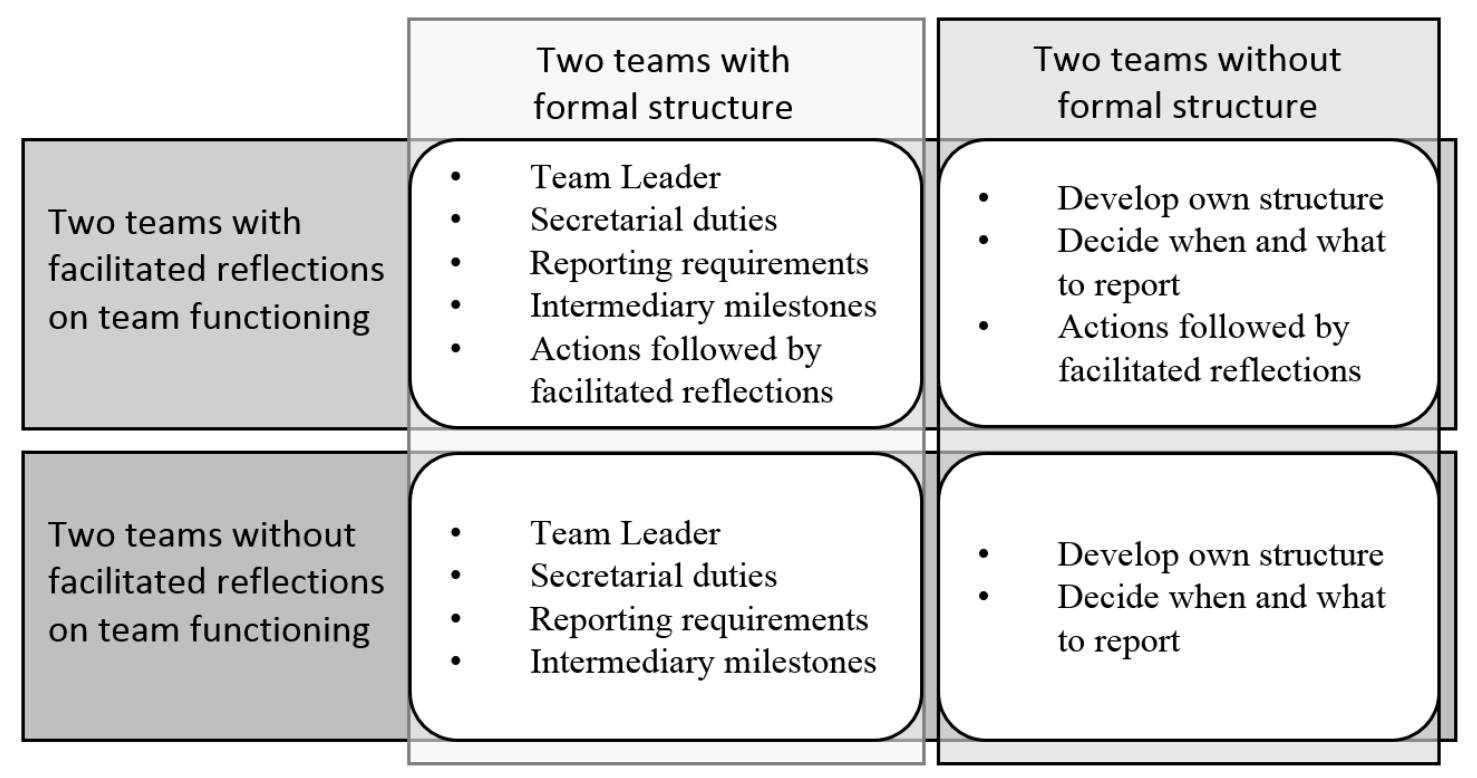

Figure 2. Virtual team structures (source: authors).

The other two virtual teams will have an informal 'structure'. This means that they will be unstructured and expected to self-organise to achieve their ultimate goal as well as to report on the structures that were adopted, if any, in order to produce the required deliverables. This approach is also legitimate. From a complex systems thinking perspective, both formal and informal aspects of organisations are important [53]. Further, the variability and complexity of subgroups and their members, and the design and patterns of relationships and communication are important drivers of intra- and inter-organisational coordination [51], so too for understanding how superordinate group identities emerge.

Each virtual team will be told that their ultimate goal is to produce a proposal for a small ( $>\$ 10$ million USD but $<\$ 50$ million USD), multi-country, 'bankable' climate change adaptation project (see Supplementary Materials File S4 for more details on the instructions that will be given to teams). According to Poole and Zhang [64], the key dimensions of tasks in virtual teams are: (a) whether the task is ongoing or a single-time project, (b) the degree of interdependence required to complete the task, and (c) the complexity of the task itself. For this action research project, a one-off, low-medium complexity task will be undertaken over the course of six months. The proposals developed by each virtual team will target submission to the GCF and aim to scale-up SPREP's first GCF project, 'Climate Information Services for Resilient Development in Vanuatu', which was approved by the GCF Board in 2016 (see [73]). The proposals should be clearly tailored to the national circumstances of other Pacific island countries and territories such as Niue or the Marshall Islands, which secured GCF readiness funds in 2018 [74]. They should also clearly demonstrate how the two ROs will coordinate on implementation. The proposals should be responsive to the GCF's six investment criteria, which are: (a) impact potential, (b) paradigm shift potential, (c) sustainable development potential, (d) recipient needs, (e) country ownership, and (f) efficiency and effectiveness (see [75]). There will be several interdependencies in the workflows of the virtual teams. Ideally, specific components of the proposal document will be designated for sole or co-authorship. We anticipate that teams will use a mix of rich and poor media in their communications (e.g., video conferencing, voice calls, emails, and data sharing) (see [69]). 


\subsection{Research Strategy}

The action research project that we propose here is loosely based on what Robinson and Mendelson ([76], p. 332) call a 'qualitative experiment', which is 'a hybrid methodological technique that fuses elements of experimental design with qualitative strategies'. However, we move away from its formal experimental structure to create a co-learning space with team members from the two ROs with the goal of initially exploring the impact of virtual team structure (and facilitated reflections, but to a lesser extent) on inter-organisational coordination. This section details our research strategy, as illustrated in Figure 3, which involves describing the population characteristics and qualitative elements of our approach. Specifically, although we have based our approach on a 'qualitative experiment', we do not cover common experimental details such as statistical power analyses, balancing checks, treatment and heterogeneous effects, or standard error adjustments. These are all typical elements of quantitative experiments, but do not apply to our action research project. This is because of our qualitative approach, as well as the qualitative data we are proposing to collect and analyse.

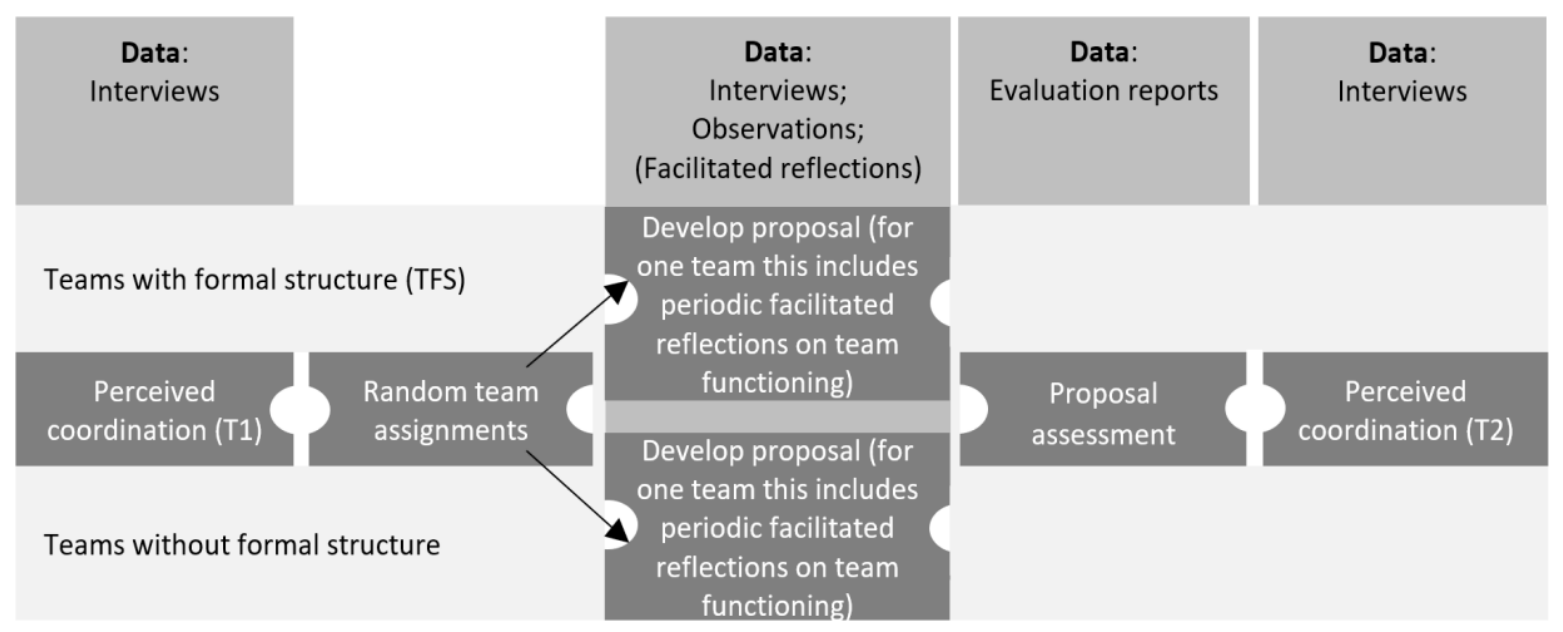

Figure 3. Overview of research strategy (source: authors).

\subsubsection{Project Implementation}

Engaging with SPC and SPREP and Selecting Co-Researchers

For SPC and SPREP, achieving sustainability rests at the core of their operations (see [77] for a discussion of the different approaches to sustainability and organisational activities). Coordination within and between them is linked to the achievement of globally agreed environment and development goals such as those contained in the 1992 United Nations Framework Convention on Climate Change, the 2015 Paris Climate Accord, and the 2030 Agenda for Sustainable Development (following [78]). The success of our action research project will rest on the creation of a strong, mutually understanding relationship between ourselves (the external researchers) and SPC and SPREP as organisations, as well as with the individuals who will work directly with us. To foster strong mutual understanding, our initial approach to the ROs will be based on clear and transparent communication, detailing an objective assessment of employee time requirements, possible risks, as well as an outline of the likely benefits of the project (this will follow the approval of our human ethics application to our respective institutional review boards). We will explain to the organisations that, because the action research project is set in a donor-funded environment, the results are likely to have many important applications in improving how inter-organisational cooperation can be enhanced in donor-funded settings. This is likely to be of particular interest to SPC and SPREP because 
they work in the context of sustainable development, and because responding to environmental and climatic changes is rapidly growing in importance, especially in the Pacific.

The external research team will contact the heads of the respective ROs, describing the research aims and objectives of enhancing coordination in the global commons area of climate change. We will also stress that we are keen to work with, and alongside, SPC and SPREP staff to learn together about the best ways that inter-organisational coordination can be enhanced. Upon reaching a provisional agreement on the scope of the research and other temporal elements, we will request that a contact person in each organisation be identified, with whom we will liaise. Through the two organisational liaisons, 12 individuals from each organisation who work in climate change adaptation-related areas will be identified. With agreement from their respective department heads, these 24 individuals will together participate in the action research project. The selected individuals should have (a) been working with their organisation for at least one year prior to the start of the project, (b) experience with adaptation projects in Pacific island countries and territories and/or broad development programming experience in the region, and (c) experience with writing project proposals, and preferably be familiar with the GCF and its processes, for example, in getting accredited entity status and accessing funding. This breadth of experience will provide an appropriate background for the tasks to be undertaken during the course of the study.

\section{Data Collection and Instruments}

In order to maximise insights into how virtual teams function (as well as the role of facilitation, although to a lesser extent), this action research project will collect qualitative data through a range of different, yet complementary instruments. These instruments will include semi-structured interviews with our co-researchers, surveys and observations during virtual team meetings (Supplementary Materials Files S5-S7 provide more details). We will interview each of our co-researchers both at the beginning and at the end of the study (at points T1 and T2 in Figure 3). This will be an opportunity for gaining insights into the individual and situational characteristics and will be used to help understand influences on inter-organisational coordination. The interview questions will be designed to encourage co-researchers to express their own thoughts and perceptions about levels of coordination and communication between SPC and SPREP at an organisational level and between individuals within the two organisations. We will use a standardised topic guide as the basis for each interview (see [79]). The questions in the topic guide will be informed by the literature on organisations, coordination, and collaboration (e.g., see [79]).

External Researchers' Participation in the Study

As far as practicable, we will actively participate in the meetings held by the four teams. With team members' prior consent, all meetings will be recorded, and the recordings will be used by the external researchers for further analysis. Where possible, this will include video recordings to assist with identifying speakers. Confidentiality will be maintained throughout the process through the use of pseudonyms in any resulting publications [79]. To simplify the process of analysing meeting recordings, qualitative data will be collected according to a pre-agreed structured observation schedule. The observation schedule will include both time and target time sampling. We will record the discussions and/or activities at specific intervals (e.g., every $15 \mathrm{~min}$ after the official start of the meeting) and at pre-selected moments (e.g., when a team member speaks for the first time in that meeting). Transcripts of the recordings will be made according to this schedule. This approach will enable co-researcher actions and interactions to be systematically recorded and classified (e.g., see [80]). The data from meeting recordings will be supplemented with notes that we take during meetings about, for example, team members who led and/or dominated discussions, 
and/or those who volunteered for activities, as well as about discussions of responsibilities, milestones, and team structure (see e.g., [81]).

As part of a general reflection process, in line with our action research approach (see [30]), we will invite our co-researchers to complete a short, written survey three months after the research begins (see Supplementary Materials File S6). The survey will comprise up to 10 questions. The questions will target co-researchers' perceptions of how effectively they see the virtual teams coordinating as well as the challenges to and opportunities for enhanced coordination.

The primary advantage of using semi-structured interviews at the T1 and T2 marks is that these interviews will give each individual the opportunity to freely describe their own views and experience without being constrained by the biases or pre-judgements of the rest of the co-research team. The main disadvantage of semi-structured interviews is that they are time and resource intensive (e.g., the effort to conduct and analyse data from a single qualitative semi-structured interview is likely to be similar to the effort required to administer and analyse several hundred quantitative surveys). Semi-structured interview data, however, provides a depth of understanding that will be vital for corroborating and adding to the survey data gathered at the three-month mark (e.g., see [82,83]). To ensure that the planned semi-structured interviews capture as much relevant information as possible, we will conduct these as face-to-face meetings with our co-researchers, providing that there are no international restrictions on travel at that time.

\section{Data Processing and Storage}

Data will be collected over the course of six months, though the entire project will run for 18 months (see Section 4.6 for the calendar/project implementation schedule). The schedule includes three months for data processing, which will begin as soon as the first data becomes available, and will be an ongoing process [84]. As part of the reflection process, the early and continuous processing of data will allow new insights and questions to be developed over the course of the project.

Following Phillippi and Lauderdale [83], notes taken during and outside the context of the virtual team meetings will be analysed as well as expanded on and organised both during and immediately following the relevant events. Our focus will be on recording key statements used in interviews. These will form a basis for expanding our analysis. To transform raw notes into well-organised notes for analysis, we will order the data in relation to our three research questions (see $[85,86]$ ). Further, the list of questions in our interview topic guide will serve as an initial set of codes. We will read through the expanded notes of our interviews and/or transcripts to add to this list of codes (see [87]). Because of the action-reflection nature of action research, we anticipate that unexpected topics are likely to emerge during interviews and during reflection periods, and we will develop codes for these topics during our analysis. We will also review our data several times before finalising the coding system.

There are two key steps that we will take to keep the data confidential. The first is that data collection instruments such as the semi-structured interview topic guide and notes will not contain information that could be used to readily identify co-researchers. Further, their names will be replaced with codes/pseudonyms for any third-party analysis and for any publication of results (see [84]). In general, as per Allen [84], using study codes is an effective method for protecting the confidentiality of those involved in research projects. The second step that we will take to ensure data confidentiality is to store all the data collected and processed, including interview transcripts, in a password-protected folder in the cloud. Where physical records are maintained, they will be kept in locked filing cabinets at one of the external researcher's home university (see [84]). Only authorised members of the research team will have access to these files, whether virtually or physically. All data will be stored for seven years after the results 
of the study have been published. They will be destroyed thereafter. The processed data will be owned by the external researchers.

\subsubsection{Empirical Analyses}

Quantitative Analysis

There are a number of quantitative steps that will not be taken as part of our action research project. These steps include balancing checks, estimating causal effects, determining a broad theory of action regarding these effects, and adjusting for standard error. We have highlighted these quantitative elements here, despite the overall qualitative nature of the action research, since we see this as a pilot study that will inform future research both in the Pacific and in the other two SIDS regions (the Atlantic and Indian Oceans, and the Caribbean). For a future research agenda, we expect that this qualitative action research project will serve as a foundation on which to design qualitative and/or quantitative field experiments based on randomized controlled trials in order to explicitly test hypotheses relating to coordination between ROs.

Qualitative Analysis

Interview data: Data collected from semi-structured interviews, originally captured through an audio recording device, will be transcribed and integrated into NVivo ${ }^{\circledR}$ (QSR International: Melbourne, Australia) [88]. NVivo ${ }^{\circledR}$ is a software package used to analyse qualitative research data, including from organisational research [89]. It is designed as a tool for bringing order and structure to rich in-depth data [88]. Once transcribed and integrated into NVivo ${ }^{\circledR}$, data will then be coded based on predefined themes relating to, for example, co-researchers' perceptions of levels of coordination, both at the individual and organisational levels. Although interview data will be anonymous, each interview transcript will be coded and attached to a pseudonym given to each co-researcher. This pseudonym will help to connect interview data with the teams to which each individual was assigned. This is important, as interview data captured at T1 will be compared to interview data captured at T2, so as to allow the external research team to detect any changes in the perceptions of coordination and engagement with other teams that have taken place over the course of the study.

Observational data: Observational data in the form of researcher notes and video recordings will also be integrated into NVivo ${ }^{\circledR}$ and coded into predefined themes relating to context and participant behaviour (attitudes towards the other, organic role(s) in team(s), etc.) (see [88,89]). Observational data will be used to help identify key moments, actions or behaviours that have resulted in change, or lack thereof. It will be used to ground the interview data and to better understand whether our action research has, in fact, identified and/or resulted in changes in levels or effectiveness of inter-organisational coordination. The observational data will also give indications as to whether any observed changes in coordination may have been the result of extraneous factors such as a significant change in the environment in which the virtual teams are operating.

Proposal evaluations: To add to the insights gained during the virtual team meetings and GCF proposal preparation, the proposals developed by each team will be judged by a panel of three independent experts. The panel will be asked to evaluate the proposals developed by the virtual teams against a set of criteria (see Supplementary Materials File S8 for more details). They will check for the conformity of the proposals to the GCF guidelines. They will also assess the quality of the proposals. Each expert will represent one of the three SIDS regions-the Atlantic and Indian Oceans, the Caribbean, and the Pacific. They will have international standing with 15 or more years of related SIDS experience. We will brief the experts verbally and in writing before they begin the evaluations in order to ensure that they have a good understanding 
of the research objectives, our action research approach, and the general evaluation guidelines. For each funding proposal developed, panel members will individually complete an evaluation form, award marks and provide comments. The panel will convene virtual meetings, if necessary, to examine and compare their evaluations and marks in a given area, to review the proposals with respect to each other and, in specific cases (e.g., equal scores), to make recommendations on a priority order and/or on possible clustering or combination of proposals. Each virtual team that participates in the study will receive an evaluation summary report. The report will reflect the evaluation results on each block of criteria, provide overall comments, and give a final overall score for the proposal. Evaluators will be advised that the comments they record should give sufficient and clear reasons for their scores.

\subsection{Research Team}

This action research project will be implemented by a team of three researchers external to SPC and SPREP and who are based in Australia, Vietnam, and the United States. All three researchers earned their $\mathrm{PhD}$ degrees in an Environmental Science/Studies field. Together, they have over 40 years of work experience outside of academia. They have also individually consulted for some of the major multilateral climate change adaptation donors, including the World Bank, the Asian Development Bank, the Commonwealth Secretariat and various bilateral agencies, giving them practical, hands-on experience with how multilateral and bilateral organisations work on-the-ground. The external research team will share the responsibility for implementing project tasks equally, including engaging the ROs, working with the virtual teams, gathering, analysing and interpreting collected data, validating the results with co-researchers, and writing up and visualising the results for publication in a high-quality peer-reviewed journal. The published article will, among other things, discuss methodological challenges and opportunities related to applying an action research approach to questions of coordination between sustainability focused ROs. The purpose of this discussion will be to advance methodological discourses about action research, about ROs and about the ways in which climate change adaptation projects are developed and implemented in SIDS. The researcher based in Australia, due to their geographic closeness to New Caledonia and Samoa (where SPC and SPREP are headquartered, respectively), will take the lead on directly interfacing and/or travelling to meet with RO officials in person, after the first kick-off meeting is held. There will be no research assistants.

\subsection{Deliverables}

The three main products of this research will be (a) four project funding proposals developed by the virtual teams. All proposals that meet the approval of the independent judging panel will be submitted to the GCF, possibly with recommended changes or amalgamations, (b) a journal article, and (c) two policy briefs. With particular respect to (c), we will develop one policy brief for disseminating our results to SPC and SPREP as well as to other interested ROs, and another to multilateral donors such as the GCF. Drawing on the insights gained during the course of the research project and the evaluation of the proposals developed, the brief for the ROs will make recommendations for the ways in which inter-organisational coordination can be improved and why it is important for the effectiveness and sustainability of future climate change investments. Likewise, the brief directed toward multilateral donors will provide recommendations for increasing member states' direct access to multi-country climate change adaptation project funds.

\subsection{Calendar/Project Implementation Schedule}

Full implementation of this action research project will take 18 months, including six months working together with the virtual teams. Three months have been allowed for the initial engagement with SPC and SPREP, and another three months for analysing and interpreting the data collected. The tasks to 
be completed are shown in Figure 4. Estimated start and completion dates are 1 January 2022 and 30 June 2023, respectively.

\begin{tabular}{|c|c|c|c|c|c|c|c|c|c|c|c|c|c|c|c|c|c|c|}
\hline & $\begin{array}{c}\mathbf{M} \\
1 \\
\end{array}$ & $\begin{array}{c}\mathbf{M} \\
2 \\
\end{array}$ & $\begin{array}{c}\mathbf{M} \\
\mathbf{3} \\
\end{array}$ & $\begin{array}{c}M \\
4 \\
\end{array}$ & $\begin{array}{c}\mathbf{M} \\
\mathbf{5}\end{array}$ & $\begin{array}{c}M \\
6 \\
\end{array}$ & $\begin{array}{c}\text { M } \\
7\end{array}$ & $\begin{array}{c}\mathbf{M} \\
\mathbf{8} \\
\end{array}$ & $\begin{array}{c}M \\
9 \\
\end{array}$ & $\begin{array}{l}M \\
10 \\
\end{array}$ & $\begin{array}{l}M \\
11 \\
\end{array}$ & $\begin{array}{l}M \\
12 \\
\end{array}$ & $\begin{array}{l}M \\
13 \\
\end{array}$ & $\begin{array}{l}M \\
14 \\
\end{array}$ & $\begin{array}{l}M \\
15 \\
\end{array}$ & $\begin{array}{l}M \\
16 \\
\end{array}$ & $\begin{array}{l}\text { M } \\
17 \\
\end{array}$ & $\begin{array}{l}\text { M } \\
18 \\
\end{array}$ \\
\hline \multicolumn{19}{|l|}{1} \\
\hline \multicolumn{19}{|l|}{2} \\
\hline \multicolumn{19}{|l|}{3} \\
\hline \multicolumn{19}{|l|}{4} \\
\hline \multicolumn{19}{|l|}{5} \\
\hline \multicolumn{19}{|l|}{6} \\
\hline \multicolumn{19}{|l|}{7} \\
\hline 8 & & & & & & & & & & & & & & & & & & \\
\hline \multicolumn{19}{|c|}{$\begin{array}{l}1 \text { Applying for Institutional Review Board approval, and engaging the ROs: writing letters, setting } \\
\text { up telephone meetings, conducting in-person meetings (including the first kick-off meeting), } \\
\text { setting up the research, and conducting the pre-test }\end{array}$} \\
\hline \multicolumn{19}{|c|}{$\begin{array}{l}2 \text { Conducting the study: observing virtual meetings, facilitating reflections, and conducting the } \\
\text { post-test }\end{array}$} \\
\hline \multicolumn{19}{|c|}{3 Evaluating whether the project proposals are 'bankable' (external evaluators) } \\
\hline \multicolumn{19}{|c|}{4 Analysing and interpreting the data collected } \\
\hline \multicolumn{19}{|c|}{5 Validating the results with co-researchers } \\
\hline \multicolumn{19}{|c|}{6 Writing up and visualising the results in a draft journal article manuscript } \\
\hline \multicolumn{19}{|c|}{7 Submitting the manuscript to a journal } \\
\hline \multicolumn{19}{|c|}{8 Developing the policy briefs for the (a) I } \\
\hline
\end{tabular}

Figure 4. Calendar/project implementation schedule over 18 months (source: authors).

\subsection{Budget}

It is estimated that implementing the research project will cost $\$ 72,853$ USD, which includes the cost for external researcher travel to New Caledonia and Samoa (where SPC and SPREP are headquartered, respectively), a contribution to the ROs for lost staff time, honoraria for the independent judging panel members, and communication and software costs (see Supplementary Materials File S9 for itemised costs). We intend to apply for funding from bilateral organisations such as Australia's Department of Foreign Affairs and Trade, and from various multilateral organisations, including the Asian Development Bank and the GCF that have a vested interest in Member States being able to access adaptation funding. It is also anticipated that the external researchers will also be partially funded by their respective universities, which will assist in covering the cost of their time and travel.

\section{Discussion}

To the best of our knowledge, there is no research published in the academic literature describing action research for studying the impact of virtual team structure on coordination between sustainability focused ROs. This paper, therefore, represents an innovation, with previous studies typically examining 
virtual team performance and success markers in profit-making, multinational enterprises (e.g., see [26,27]). The use of a co-learning and 'common endeavour' approach will foster insights, learnings, and offer action-oriented solutions that span disciplinary and organisational boundaries. This is because action research focuses on the use of a curious and open mind, without having strongly pre-conceived ideas about what results will be found [30]. Because the action research approach means that the external researchers will work together with co-researchers/team members from the two participating ROs, the research component will quickly become a normalised part of daily routines.

The action research approach proposed in this paper combines some elements typical of what are referred to as field experiments, with qualitative data to add to the workday outputs. Pure field experiments, though considered by some as 'the sterling-gold standard of organizational research methods' ([90], p. 91), have a number of disadvantages. For example, they are often carried out on the assumption that manipulation and observation of objects and parameters can be fully controlled (e.g., see [91]). In contrast, and in our proposed action research, we do not seek to control and isolate variables, but rather to gain insights and allow for unexpected results and developments to surface. We will gather qualitative data through semi-structured interviews with co-researchers, observation and analysis by the external researchers, as well as through short surveys (e.g., see [76,91]). A disadvantage of our approach is that it precludes a statistically robust cause and effect analysis. However, this disadvantage is heavily outweighed by the opportunities for learning-while-doing in collaboration with experts in the fields of climate change adaptation, funding proposal preparation, and with a long work history in the two participating ROs.

The other strong rationale for selecting an action research approach is that, in the context of SPC and SPREP, it will help to overcome the challenge of accessing participants as the research will be seen as a co-learning opportunity with mutual benefits for both organisations (see [92]). Issues of inter-organisational coordination are not new, with Bond [93], for example, discussing challenges in Europe with regional security organisation mandates converging over time, and the efforts to address resultant coordination issues through information exchange and common approaches in areas where mandates overlap. However, action on climate change and the tangled nature of regionalism in the Pacific could be seen as sensitive or controversial topics (e.g., see [94]). As a result, there may be an unwillingness on the part of the organisations and staff to participate in the proposed study. This could particularly be the case, given the small number of officials in both organisations dedicated to climate change adaptation activities. Thus, even requesting 12 personnel from each organisation for the study for a period of six months may be a 'big ask'. In this regard, securing the support of the directors-general and then the heads of department by putting forward a strong business case that demonstrates the benefits of enhanced inter-organisational coordination for achieving their organisational objectives and sustainability in the region will be important.

In addition to discussing the business case of our research when we approach the directors-general and heads of department, we will also ensure that we clearly describe how we intend to work alongside the team members, learning together with them. We will be asking SPC and SPREP to commit staff time to the research, and in order to make this more attractive, we will seek funding from external donors, such as from Australia's Department of Foreign Affairs and Trade, the Asian Development Bank, and the GCF, that can be used to pay for or help offset the cost of the time that staff will spend participating in the research. Because of the strong links between coordination among ROs and the degree to which they achieve their goals, there is a firm foundation for seeking this funding. We already have strong networks in the Pacific region that we will use in order to make contact with the directors-general of SPC and SPREP, as well as for gaining some initial insights into the most efficient and effective ways of working with co-researchers.

Notwithstanding the potential challenge in accessing participants, there are two additional risks associated with this project. First, the virtual teams may not be truly independent of each other, as members are almost certain to interact outside the confines of the project. While this could be a problem for a purely 
experimental setup, in the case of an action research project, it is unlikely to significantly affect the insights gathered. The second risk is that large volumes of data are likely to be generated during the study (e.g., if one team meets on a weekly basis for the six-month duration of the project, the researchers will have recordings of approximately 24 meetings to analyse just for that one team). The qualitative nature of the action research, combined with our observation schedule, will help to address this risk through the use of time-based sampling methods.

This paper proposes the creation of four inter-organisational virtual teams that will operate for a period of six months. Virtual teams, however, can be difficult to manage due to a number of factors, including time zone differences, language barriers, cultural differences, leadership and communication challenges, and technological capacities [95]. Further, the more geographically-dispersed the teams are, the more complex the coordination becomes. The fact that SPC and SPREP are headquartered in New Caledonia and Samoa, respectively, geographical dispersion could be a challenge. However, given that the time difference between them is only three hours, identifying convenient meeting times should be less of a challenge. To maintain consistency, virtual team membership will be fixed so that role and task expectations and standard operating procedures can be developed and agreed to-co-researchers will only be replaced if they leave the organisation, are transferred to a different department, or otherwise become unavailable. To ensure that teams have some degree of autonomy, there will be no external authority line or external team linkages as these will complicate team members' responsibilities and can reduce their commitment [64]. The external researchers will form the link between the virtual teams and the organisations' executive management teams. While there are a few risks associated with this study, advance planning will help mitigate their impact.

Our results will provide an important step in real-world understandings of the role of virtual team structure and facilitation for coordinated work. Additionally, the study will form a foundation for the implementation of qualitative and quantitative field experiments such as randomized controlled trials that would seek to statistically measure the level of coordination between ROs that are prioritising adaptation and sustainability activities in the Pacific as well as in other SIDS regions.

\section{Conclusions}

This paper had one central aim-to propose and discuss an action research approach for gaining insights into the level of coordination between SPC and SPREP, two of the four regional organisations at the forefront of climate action in the Pacific. The research is designed to focus on whether or not virtual team structure (and facilitation, but to a lesser extent) influences coordination of adaptation across small, dispersed, resource-constrained country jurisdictions in the Pacific region. While not presenting empirical findings, this paper represents an important intermediary step in ensuring the development of more robust, climate-related organisational policies at the regional scale in the Pacific. Once implemented, the results of the research will be a crucial resource for more detailed investigations, and for guiding decisions on the cost-effectiveness and distributional impacts of climate finance investments more broadly.

Supplementary Materials: The following are available online at http://www.mdpi.com/2078-1547/11/1/8/s1.

Author Contributions: Conceptualization, D.G., S.-a.R. and H.B.; Methodology, D.G., S.-a.R. and H.B.; Software, D.G., S.-a.R. and H.B.; Validation, D.G., S.-a.R. and H.B.; Formal analysis, D.G., S.-a.R. and H.B.; Investigation, D.G., S.-a.R. and H.B.; Resources, D.G., S.-a.R. and H.B.; Data curation, D.G., S.-a.R. and H.B.; Writing-original draft preparation, D.G., S.-a.R. and H.B.; Writing-review and editing, D.G., S.-a.R. and H.B.; Visualization, D.G. and H.B.; Supervision, D.G.; Project administration, D.G.; Funding acquisition, D.G., S.-a.R. and H.B. All authors have read and agreed to the published version of the manuscript.

Funding: This research received no external funding.

Acknowledgments: The authors would like to thank JTR, JG and the anonymous reviewers, all of whom provided helpful comments on earlier versions of this paper. 
Conflicts of Interest: The authors declare no conflict of interest.

\section{References}

1. Robinson, S.-A.; Gilfillan, D. Regional organisations and climate change adaptation in small island developing states. Reg. Environ. Chang. 2017, 17, 989-1004. [CrossRef]

2. UN-OHRLLS. About SIDS: Country Profiles. Available online: https://bit.ly/2LwEUGF (accessed on 18 June 2015).

3. Nurse, L.A.; McLean, R.F.; Agard, J.; Briguglio, L.P.; Duvat-Magnan, V.; Pelesikoti, N.; Tompkins, E.; Webb, A. Small islands. In Climate Change 2014: Impacts, Adaptation, and Vulnerability. Part B: Regional Aspects. Contribution of Working Group II to the Fifth Assessment Report of the Intergovernmental Panel on Climate Change; Barros, V.R., Field, C.B., Dokken, D.J., Mastrandrea, M.D., Mach, K.J., Bilir, T.E., Chatterjee, M., Ebi, K.L., Estrada, Y.O., Genova, R.C., et al., Eds.; Cambridge University Press: Cambridge, UK, 2014; pp. 1613-1654.

4. Nunn, P.D.; McLean, R.; Dean, A.; Fong, T.; Iese, V.; Katonivualiku, M.; Klöck, C.; Korovulavula, I.; Kumar, R.; Tabe, T. Adaptation to Climate Change: Contemporary Challenges and Perspectives. In Climate Change and Impacts in the Pacific; Kumar, L., Ed.; Springer International Publishing: Cham, Switzerland, 2020; pp. 499-524. [CrossRef]

5. Robinson, S.-A. Climate change adaptation in small island developing states: Insights and lessons from a meta-paradigmatic study. Environ. Sci. Policy 2018, 85, 172-181. [CrossRef]

6. Robinson, S.-A.; Wren, C. Geographies of vulnerability: A research note on human system adaptations to climate change in the Caribbean. Geografisk Tidsskrift-Danish J. Geogr. 2020. [CrossRef]

7. IPCC. Annex II: Glossary. In Climate Change 2014: Impacts, Adaptation, and Vulnerability. Part B: Regional Aspects. Contribution of Working Group II to the Fifth Assessment Report of the Intergovernmental Panel on Climate Change; Barros, V.R., Field, C.B., Dokken, D.J., Mastrandrea, M.D., Mach, K.J., Bilir, T.E., Chatterjee, M., Ebi, K.L., Estrada, Y.O., Genova, R.C., et al., Eds.; Cambridge University Press: Cambridge, UK, 2014; pp. 1757-1776.

8. Gerlak, A.K.; Guido, Z.; Vaughan, C.; Rountree, V.; Greene, C.; Liverman, D.; Trotman, A.R.; Mahon, R.; Cox, S.-A.; Mason, S.J.; et al. Building a Framework for Process-Oriented Evaluation of Regional Climate Outlook Forums. Weather Clim. Soc. 2018, 10, 225-239. [CrossRef]

9. Hewitson, B.C.; Janetos, A.C.; Carter, T.R.; Giorgi, F.; Jones, R.G.; Kwon, W.T.; Mearns, L.O.; Schipper, E.L.F.; van Aalst, M. Regional context. In Climate Change 2014: Impacts, Adaptation, and Vulnerability. Part B: Regional Aspects. Contribution of Working Group II to the Fifth Assessment Report of the Intergovernmental Panel of Climate Change; Barros, V.R., Field, C.B., Dokken, D.J., Mastrandrea, M.D., Mach, K.J., Bilir, T.E., Chatterjee, M., Ebi, K.L., Estrada, Y.O., Genova, R.C., et al., Eds.; Cambridge University Press: Cambridge, UK, 2014; pp. 1133-1197.

10. Maclellan, N. Improving Access to Climate Financing for the Pacific Islands; Lowy Institute for International Policy: Sydney, Australia, 2011; pp. 1-40.

11. Fry, G. Framing the Islands: Power and Diplomatic Agency in Pacific Regionalism; ANU Press: Canberra, Australia, 2019. [CrossRef]

12. Robinson, S.-a.; Dornan, M. International financing for climate change adaptation in small island developing states. Reg. Environ. Chang. 2017, 17, 1103-1115. [CrossRef]

13. Dornan, M.; Newton-Cain, T. Regional Service Delivery among Pacific Island Countries: An Assessment. Asia Pac. Policy Stud. 2014, 1, 541-560. [CrossRef]

14. Robinson, S.-a. Mainstreaming climate change adaptation in small island developing states. Clim. Dev. 2019, 11, 47-59. [CrossRef]

15. Bryar, T.; Naupa, A. The Shifting Tides of Pacific Regionalism. Round Table 2017, 106, 155-164. [CrossRef]

16. Haas, E.B. When Knowledge Is Power: Three Models of Change in International Organizations; University of California Press: Berkeley, CA, USA, 1990.

17. Beattie, A. The Governance of Priorities, Financing and Perfromance in the Delivery of Public Goods by International and Regional Membership Organisations; Pacific Islands Forum Secretariat: Suva, Fiji, 2013.

18. Price, J.L. Handbook of Organizational Measurement; D. C. Heath and Company: Lexington, KY, USA, 1972.

19. Etzioni, A. Modern Organizations; Prentice Hall: Englewood Cliffs, NJ, USA, 1964. 
20. SPREP. SPC and SPREP Seal Partnership for Resilient and Sustainable Pacific Development. Available online: https://bit.ly/2TgPIUA (accessed on 18 February 2018).

21. PIF Secretariat. 48th Pacific Islands Forum Leaders Communiqué. Available online: https://bit.ly/2TCe58R (accessed on 18 February 2018).

22. Khan, M.; Robinson, S.; Weikmans, R.; Ciplet, D.; Roberts, J.T. Twenty-five years of adaptation finance through a climate justice lens. Clim. Chang. 2019. [CrossRef]

23. Gilfillan, D. Governance Limits to Adaptation in Cambodia's Health Sector. In Limits to Climate Change Adaptation; Leal Filho, W., Nalau, J., Eds.; Springer International Publishing: Cham, Switzerland, 2017; pp. 25-39. [CrossRef]

24. PIF Secretariat. The Framework for Pacific Regionalism; Pacific Islands Forum Secretariat: Suva, Fiji, 2014 ; pp. 1-12.

25. Gilson, L.L.; Maynard, M.T.; Young, N.C.J.; Vartiainen, M.; Hakonen, M. Virtual Teams Research: 10 Years, 10 Themes, and 10 Opportunities. J. Manag. 2014, 41, 1313-1337. [CrossRef]

26. Helge, L.; Victor, D. A profile of high-performing global virtual teams. Team Perform. Manag. Int. J. 2017. [CrossRef]

27. Lurey, J.S.; Raisinghani, M.S. An empirical study of best practices in virtual teams. Inf. Manag. 2001, 38, 523-544. [CrossRef]

28. Wicks, P.G.; Reason, P.; Bradbury, H. Living Inquiry: Personal, Political and Philosophical Groundings for Action Research Practice. In The SAGE Handbook of Action Research: Participative Inquiry and Practice, 2nd ed.; Reason, P., Bradbury, H., Eds.; SAGE Publications: Thousand Oaks, CA, USA; New Delhi, India, 2008; pp. 15-30.

29. Swantz, M.L. Participatory Action Research as Practice. In The SAGE Handbook of Action Research: Participative Inquiry and Practice, 2nd ed.; Reason, P., Bradbury, H., Eds.; SAGE Publications: Thousand Oaks, CA, USA; New Delhi, India, 2008; pp. 31-48.

30. Reason, P.; Bradbury, H. Introduction. In The SAGE Handbook of Action Research: Participative Inquiry and Practice, 2nd ed.; Reason, P., Bradbury, H., Eds.; SAGE Publications: Thousand Oaks, CA, USA; New Delhi, India, 2008; pp. $1-10$.

31. Robinson, S.-A. Climate change adaptation in SIDS: A systematic review of the literature pre and post the IPCC Fifth Assessment Report. Wiley Interdiscip. Rev. Clim. Chang. 2020, e653, 1-21. [CrossRef]

32. Mackewn, J. Facilitation as Action Research in the Moment. In The SAGE Handbook of Action Research: Participative Inquiry and Practice, 2nd ed.; Reason, P., Bradbury, H., Eds.; SAGE Publications: Thousand Oaks, CA, USA; New Delhi, India, 2008; pp. 615-628.

33. Wilkinson, M. The Secrets of Facilitation: The S.M.A.R.T. Guide to Getting Results with Groups; Jossey-Bass: San Francisco, CA, USA, 2004.

34. Raelin, J.A. The Role of Facilitation in Praxis. Org. Dyn. 2006, 35, 83-95. [CrossRef]

35. Kolfschoten, G.L.; Niederman, F.; Briggs, R.O.; de Vreede, G.-J. Facilitation Roles and Responsibilities for Sustained Collaboration Support in Organizations. J. Manag. Inf. Syst. 2012, 28, 129-162. [CrossRef]

36. Griffith, T.L.; Fuller, M.A.; Northcraft, G.B. Facilitator Influence in Group Support Systems: Intended and Unintended Effects. Inf. Syst. Res. 1998, 9, 20-36. [CrossRef]

37. Dix, A. Theoretical analysis and theory creation. In Research Methods for Human-Computer Interaction; Cox, A.L., Cairns, P., Eds.; Cambridge University Press: Cambridge, UK, 2008; pp. 175-195. [CrossRef]

38. Schultz, M.; Soderbaum, F.; Ojendal, J. Introduction: A Framework for Understanding Regionalization. In Regionalization in a Globalizing World; Schultz, M., Soderbaum, F., Ojendal, J., Eds.; Zed Books: London, UK, 2001; pp. 1-21.

39. Soderbaum, F. Rethinking Regionalism; Palgrave Macmillan: New York, NY, USA, 2016.

40. Engel, U.; Zinecker, H.; Mattheis, F.; Dietze, A.; Plotze, T. Introduction: The challenge of emerging regionalisms outside of Europe. In The New Politics of Regionalism: Perspectives from Africa, Latin America and Asia-Pacific; Engel, U., Zinecker, H., Mattheis, F., Dietze, A., Plotze, T., Eds.; Routledge: Abingdon, UK, 2017; pp. 1-15.

41. Kirkman, B.L.; Mathieu, J.E. The Dimensions and Antecedents of Team Virtuality. J. Manag. 2005, 31, 700-718. [CrossRef]

42. Hoch, J.E.; Kozlowski, S.W.J. Leading virtual teams: Hierarchical leadership, structural supports, and shared team leadership. J. Appl. Psychol. 2014, 99, 390-403. [CrossRef] 
43. Rapp, A.; Ahearne, M.; Mathieu, J.; Rapp, T. Managing sales teams in a virtual environment. Int. J. Res. Market. 2010, 27, 213-224. [CrossRef]

44. Söderbaum, F. Theories of Regionalism. In Routledge Handbook of Asian Regionalism; Beeson, M., Stubbs, R., Eds.; Routledge: Abingdon, UK, 2012; pp. 11-21.

45. Wunderlich, J.-U. Regionalism, Globalisation and International Order: Europe and Southeast Asia; Ashgate Publishing: Abingdon, UK; New York, NY, USA, 2007.

46. Dovers, S.R.; Hezri, A.A. Institutions and policy processes: The means to the ends of adaptation. Wiley Interdiscip. Rev. Clim. Chang. 2010, 1, 212-231. [CrossRef]

47. Hurrell, A. Regionalism in Theoretical Perspective. In Regionalism in World Politics: Regional Organization and International Order; Fawcett, L., Hurrell, A., Eds.; Oxford University Press: Oxford, UK, 1996; pp. 37-73.

48. Hurrell, A. The Regional Dimension in International Relations Theory. In Global Politics of Regionalism: Theory and Practice; Farrell, M., Hettne, B., Van Langenhove, L., Eds.; Pluto Press: London, UK, 2005; pp. 38-53.

49. Holler, J.; Bernier, Q.; Roberts, J.T.; Robinson, S.-a. Transformational adaptation in Least Developed Countries: Does expanded stakeholder participation make a difference? Sustainability 2020, 12, 1657. [CrossRef]

50. Haas, E.B. The Uniting of Europe: Political, Social, and Economical Forces, 1950-1957; Stanford University Press: Stanford, CA, USA, 1958.

51. Meadows, D.H. Thinking in Systems: A Primer; Chelsea Green Publishing Company: White River Junction, VT, USA, 2008.

52. Asopa, V.N.; Beye, G. Management of Agricultural Research: A Training Manual. Available online: https: //bit.ly/2N6CroH (accessed on 30 September 2015).

53. Haque, S.; Rehman, N. Modern organization theory: Analyzing the complexity of coordination and cooperation in the modern organizations. Int. J. Manag. Sustain. 2014, 3, 261-268.

54. Bhattacharya, D. Cross-Cultural Management: Text And Cases; PHI Learning Private Limited: New Delhi, India, 2010.

55. Flood, R.L.; Carson, E. Dealing with Complexity: An Introduction to the Theory and Application of Systems Science, 2nd ed.; Plenum Press: New York, NY, USA, 1988.

56. Kurtz, C.F.; Snowden, D.J. The new dynamics of strategy: Sense-making in a complex and complicated world. IBM Syst. J. 2003, 42, 462-483. [CrossRef]

57. Gaertner, S.L.; Dovidio, J.F. Reducing Intergroup Bias: The Common Ingroup Identity Model; Routledge: New York, NY, USA; London, UK, 2000.

58. Maloney, M.M.; Zellmer-Bruhn, M.E. Building bridges, windows and cultures: Mediating mechanisms between team heterogeneity and performance in global teams. Manag. Int. Rev. 2006, 46, 697-720. [CrossRef]

59. Gaertner, S.L.; Mann, J.; Murrell, A.; Dovidio, J.F. Reducing intergroup bias: The benefits of recategorization. J. Personal. Soc. Psychol. 1989, 57, 239-249. [CrossRef]

60. Gaertner, S.L.; Dovidio, J.F. The Aversive Form of Racism. In Stereotypes and Prejudice: Essential Readings; Stangor, C., Ed.; Psychology Press: Philadelphia, PA, USA, 2000; pp. 289-304.

61. Burlig, F. Improving transparency in observational social science research: A pre-analysis plan approach. Econ. Lett. 2018, 168, 56-60. [CrossRef]

62. Ravasio, P.; Guttormsen-Schar, S.; Tscherter, V. The Qualitative Experiment in HCI: Definition, Occurrences, Value and Use. ACM Trans. Comput.-Hum. Interact. 2004, 5, 1-24.

63. Friedman, V.J.; Rogers, T. Action Science: Linking Causal Theory and Meaning Making in Action Research. In The SAGE Handbook of Action Research: Participative Inquiry and Practice, 2nd ed.; Reason, P., Bradbury, H., Eds.; SAGE Publications: Thousand Oaks, CA, USA; New Delhi, India, 2008; pp. 252-265.

64. Nolte, D. Latin America's New Regional Architecture: A Cooperative or Segmented Regional Governance Complex? European University Institute: Fiesole, Italy, 2014; pp. 1-34. [CrossRef]

65. Gilfillan, D. Climate Change Adaptation and Health in Southeast Asia: What Do Regional Organisations Contribute? The Australian National University: Canberra, Australia, 2018.

66. Poole, M.S.; Zhang, H. Vitural Teams. In The Handbook of Group Research and Practice; Wheelan, S.A., Ed.; SAGE Publications: Thousand Oaks, CA, USA, 2005; pp. 363-384. 
67. Ortiz de Guinea, A.; Webster, J.; Staples, D.S. A meta-analysis of the consequences of virtualness on team functioning. Inf. Manag. 2012, 49, 301-308. [CrossRef]

68. Cohen, S.G.; Gibson, C.B. In the Beginning: Introduction and Framework. In Virtual Teams That Work: Creating Conditions for Virtual Team Effectiveness; Gibson, C.B., Cohen, S.G., Eds.; Jossey-Bass: San Francisco, CA, USA, 2003; pp. 1-16.

69. Kirkman, B.L.; Rosen, B.; Tesluk, P.E.; Gibson, C.B. The impact of team empowerment on virtual team performance: The moderating role of face-to-face interaction. Acad. Manag. J. 2004, 47, 175-192. [CrossRef]

70. Suh, A.; Shin, K.-S. Exploring the effects of online social ties on knowledge sharing: A comparative analysis of collocated vs dispersed teams. J. Inf. Sci. 2010, 36, 443-463. [CrossRef]

71. Rice, R.E.; Gattiker, U.E. New Media and Organizational Structuring. In The New Handbook of Organizational Communication; Jablin, F.M., Putnam, L.L., Eds.; Sage Publications: Thousand Oaks, CA, USA, 2001; pp. 544-582. [CrossRef]

72. Suh, K.S. Impact of communication medium on task performance and satisfaction: An examination of media-richness theory. Inf. Manag. 1999, 35, 295-312. [CrossRef]

73. O'Flynn, J.; Wanna, J. (Eds.) Collaborative Governance: A New Era of Public Policy in Australia? ANU Press: Canberra, Australia, 2013.

74. GCF. Projects and Programmes: Climate Information Services for Resilient Development in Vanuatu. Available online: https://bit.ly/2PILPjB (accessed on 21 February 2018).

75. GCF. Readiness and Preparatory Support Programme: Progress Report; Green Climate Fund: Songdo, Korea, 2018; pp. $1-44$.

76. GCF. Annex III: Initial Investment Framework. Available online: https://bit.ly/2PGpCmn (accessed on 17 February 2018).

77. Wikström, P.-A. Sustainability and organizational activities-Three approaches. Sustain. Dev. 2010, 18, 99-107. [CrossRef]

78. Balsiger, J.; VanDeveer, S.D. Regional Governance and Environmental Problems. In Oxford Research Encyclopedia of International Studies; Marlin-Bennett, R., Ed.; Oxford University Press: Oxford, UK, 2010; pp. 1-27. [CrossRef]

79. Bauer, M.W.; Gaskell, G. (Eds.) Qualitative Researching with Text, Image and Sound: A Practical Handbook for Social Research; SAGE Publications Ltd.: Thousand Oaks, CA, USA, 2000. [CrossRef]

80. Purvanova, R.K.; Bono, J.E. Transformational leadership in context: Face-to-face and virtual teams. Leadersh. Quart 2009, 20, 343-357. [CrossRef]

81. Rizvi, M. Development of a classroom observation schedule for measuring the efficacy of a teacher development programme. Procedia Soc. Behav. Sci. 2010, 2, 654-660. [CrossRef]

82. Adams, A.; Cox, A.L. Questionnaires, in-depth interviews and focus groups. In Research Methods for Human-Computer Interaction; Cairns, P., Cox, A.L., Eds.; Cambridge University Press: Cambridge, UK, 2008; pp. 17-34.

83. Phillippi, J.; Lauderdale, J. A Guide to Field Notes for Qualitative Research: Context and Conversation. Qual. Health Res. 2017, 28, 381-388. [CrossRef]

84. Allen, M. (Ed.) The SAGE Encyclopedia of Communication Research Methods; SAGE Publications, Inc.: Thousand Oaks, CA, USA, 2018. [CrossRef]

85. Ward, D.J.; Furber, C.; Tierney, S.; Swallow, V. Using Framework Analysis in nursing research: A worked example. J. Adv. Nurs. 2013, 69, 2423-2431. [CrossRef]

86. Furber, C. Framework analysis: A method for analysing qualitative data. Afr. J. Midwifery Women's Health 2010, 4, 97-100. [CrossRef]

87. Rabiee, F. Focus-group interview and data analysis. Proc. Nutr. Soc. 2004, 63, 655-660. [CrossRef]

88. Richards, L. Using NVivo in Qualitative Research; SAGE Publications, Inc.: London, UK; Thousand Oaks, CA, USA; New Delhi, India, 1999.

89. Welsh, E. Dealing with Data: Using NVivo in the Qualitative Data Analysis Process. Forum Qualitative Sozialforschung/Forum Qual. Soc. Res. 2002, 3. [CrossRef]

90. Eden, D. Field Experiments in Organizations. Ann. Rev. Organ. Psychol. Organ. Behav. 2017, 4, 91-122. [CrossRef] 
91. Hoyle, R.H. Design and Analysis of Experimental Research on Groups. In The Handbook of Group Research and Practice; Wheelan, S.A., Ed.; SAGE Publications: Thousand Oaks, CA, USA, 2005; pp. 223-239.

92. Pettigrew, R.N.; Duncan, K.A. Poking a sleeping bear: The challenge of organizational recruitment for controversial topics. Community Work Fam. 2017, 20, 35-49. [CrossRef]

93. Bond, M. The EU and the Council of Europe: Difference, duplication or delegation? In Cooperation or Conflict? Problematizing Organizational Overlap in Europe; Galbreath, D.J., Gebhard, C., Eds.; Ashgate Publishing Ltd: Farnham, UK, 2010; pp. 11-28.

94. King, E.B.; Hebl, M.R.; Morgan, W.B.; Ahmad, A.S. Field Experiments on Sensitive Organizational Topics. Organ. Res. Methods 2013, 16, 501-521. [CrossRef]

95. Barnwell, D.; Nedrick, S.; Rudolph, E.; Sesay, M.; Wellen, W. Leadership of International and Virtual Project Teams. Int. J. Glob. Bus. 2014, 7, 1-8.

(C) 2020 by the authors. Licensee MDPI, Basel, Switzerland. This article is an open access article distributed under the terms and conditions of the Creative Commons Attribution (CC BY) license (http://creativecommons.org/licenses/by/4.0/). 